\title{
Association of leptin receptor polymorphism with insulin resistance
}

\author{
Ken C Chiu, Audrey Chu, Lee-Ming Chuang ${ }^{1}$ and Mohammed F Saad \\ Division of Clinical Epidemiology and Preventive Medicine, Department of Medicine, University of California, Los Angeles, School of Medicine, Los Angeles, \\ California, USA and ${ }^{1}$ Department of Internal Medicine and Graduate Institute of Clinical Medicine, National Taiwan University Hospital, Taipei, Taiwan
}

(Correspondence should be addressed to K C Chiu, 924 Westwood Boulevard, \#335, Los Angeles, California 90024, USA;

Email: kchiu@mednet.ucla.edu)

\begin{abstract}
Objective: Although the role of the leptin receptor (LEPR) in obesity is well recognized, its role in insulin sensitivity remains unknown.

Design: This was a cross-sectional study to investigate the impact of the Q223R polymorphism of the LEPR gene on insulin sensitivity.

Methods: Sixty-seven glucose-tolerant Caucasians were enrolled. The insulin sensitivity index and glucose clearance were measured using a hyperglycemic clamp. Genomic DNA was extracted for genotyping.

Results: We identified 20 QQ, 31 QR, and 16 RR subjects. The three genotypic groups were similar in age, gender distribution, body mass index, waist-hip ratio, and blood pressure, but differed in the insulin sensitivity index $(P=0.0180)$ and in glucose clearance $(P=0.0220)$. Multivariate analyses showed that the Q223R polymorphism was independently associated with the insulin sensitivity index $(P=0.0317)$ and glucose clearance $(P=0.0436)$. A trend of increasing low density lipoprotein cholesterol concentration was also observed $(P=0.0447)$.

Conclusion: We have reported the first association of the Q223R polymorphism of the LEPR gene with insulin resistance.
\end{abstract}

European Journal of Endocrinology 150 725-729

\section{Introduction}

The leptin receptor (LEPR) is a member of the cytokine receptor family, which plays a critical role in the regulation of body weight by inhibiting food intake and stimulating energy expenditure. The leptin receptor is located on chromosome $1 \mathrm{p} 31$, which has been linked to an acute insulin response in Pima Indians (1). However, no mutations within this gene were found to be responible for this linkage in Pima Indians (2). Although the linkage failed to be replicated in the same population (3), this region is also linked to diabetes and post-challenge plasma glucose concentrations in an Old Order Amish population (4) and also to the 24-h respiratory quotient in Pima Indians (5). The latter two linkage studies suggested a link between this locus and insulin resistance.

Mutated LEPR plays a crucial role in the pathogenesis of obesity and/or diabetes in $d b / d b$ mice, Zucker fatty $(f a / f a)$ rats, and Koletsky rats. Although it does not play a major role in human diseases, markers at this locus have been demonstrated to be associated with obesity/diabetes phenotypes in the human $(4,5)$. Among them, the Q223R polymorphism has been shown to affect receptor function (6). However, the relationship of this polymorphism with insulin sensitivity has not been examined as yet. In this study, we examined the impact of this polymorphism on insulin sensitivity in a group of well-characterized subjects.

\section{Subjects and methods}

The study complied with the recommendations of the Declaration of Helsinki and was approved by the Institutional Review Board. Written informed consent was obtained from each participant at entry to the study. Sixty-seven healthy Caucasian subjects $(36$ females and 31 males) were recruited from West Los Angeles through an advertisement on the campus of the University of California, Los Angeles. The detailed study protocol has been described previously (7). The demographic features of the study subjects are shown in Table 1 . They had normal glucose tolerance and were normotensive at entry to the study and then underwent a hyperglycemic clamp as described previously (8). Briefly, after an overnight fast, participants received a bolus of $50 \%$ dextrose solution $\left(11.4 \mathrm{gm} / \mathrm{m}^{2}\right)$ at $t=0 \mathrm{~min}$. Continuous infusion of $30 \%$ dextrose solution was commenced at $t=15 \mathrm{~min}$ at a variable rate which was adjusted every 5 min so as to maintain a plasma glucose concentration around $10 \mathrm{mmol} / \mathrm{l}$ toward $t=180 \mathrm{~min}$. The insulin 
Table 1 Clinical characteristics of the 67 study subjects, 36 (54\%) of whom were female.

\begin{tabular}{lccc}
\hline & Means \pm s.D. & Minimum & Maximum \\
\hline Age (years) & $27 \pm 6$ & 19 & 39 \\
Body mass index $\left(\mathrm{kg} / \mathrm{m}^{2}\right)$ & $24.17 \pm 3.95$ & 17.58 & 34.26 \\
Waist-hip ratio $\left(\mathrm{cm} / \mathrm{cm}^{2}\right)$ & $0.804 \pm 0.077$ & 0.649 & 1.033 \\
Systolic blood pressure $(\mathrm{mmHg})$ & $116 \pm 11$ & 94 & 137 \\
Diastolic blood pressure $(\mathrm{mmHg})$ & $67 \pm 8$ & 48 & 89 \\
Steady-state plasma glucose $(\mathrm{mmol} / \mathrm{l})$ & $10.06 \pm 0.35$ & 571 & 10.77 \\
First-phase insulin response $(\mathrm{pmol} / \mathrm{l})$ & $1597 \pm 917$ & 104 & 4569 \\
Second-phase insulin response $(\mathrm{pmol} / \mathrm{l})$ & $389 \pm 204$ & 1.728 & 1567 \\
Insulin sensitivity index $\left(\mu \mathrm{m} / \mathrm{m}^{2}\right.$ per min per pmol) & $7.447 \pm 3.461$ & 0.171 & 16532 \\
Glucose clearance $\left(\mathrm{l} / \mathrm{m}^{2}\right.$ per $\mathrm{min}$ per pmol) & $0.750 \pm 0.364$ & 1.774 \\
\hline
\end{tabular}

sensitivity index was calculated by dividing the average glucose infusion rate during the last $60 \mathrm{~min}$ of the clamp by the average plasma insulin level. To adjust for the mass effect of glucose during the hyperglycemic clamp, glucose clearance was defined as the insulin sensitivity index divided by the plasma glucose concentration. The coefficient of variation for steady-state plasma glucose levels was $5.8 \pm 2.4 \%$. The first-phase insulin response was the sum of plasma insulin levels during the first $10 \mathrm{~min}(t=2.5,5,7.5$, and $10 \mathrm{~min})$ and the second-phase insulin response was the average of plasma insulin levels at $t=130,140,150,160$, 170 , and $180 \mathrm{~min}$. Although the gold standard for the measurement of insulin sensitivity is the euglycemic clamp, the hyperglycemic clamp provides both insulin sensitivity and $\beta$-cell function from a single procedure. Furthermore, insulin sensitivity measured by the hyperglycemic clamp has an excellent correlation with the insulin sensitivity measured by the euglycemic clamp $(9-11)$. We therefore chose the hyperglycemic clamp for this study, which allowed us to assess insulin sensitivity and $\beta$-cell function. Genomic DNA was isolated from peripheral lymphocytes (7). Primer sequences were determined and polymerase chain reactions were performed as described previously (6).

Skewed variables were logarithmically transformed to normality before analysis. These variables were: body mass index, waist-hip ratio, plasma insulin concentrations, first-phase insulin response, second-phase insulin response, insulin sensitivity index, and glucose clearance. Differences in continuous variables between groups of subjects were tested with ANOVA. Differences in proportions were evaluated by a chi-square test or Fisher exact test, as appropriate. To examine the influence of multiple variables on the insulin sensitivity index or glucose clearance, a stepwise regression analysis using general linear models was performed with a backward stepwise option as described previously (7). A nominal $P$ value of less than 0.05 was considered significant. Data are presented as arithmetic means \pm S.D. unless otherwise specified. SYSTAT 10.0 for Windows from SPSS Inc. (Chicago, IL, USA) was used for statistical analysis.

\section{Results}

This study included 67 glucose-tolerant and normotensive subjects, confirmed by a standard $75 \mathrm{~g}$ oral glucose tolerant test with blood pressure $<140 / 90 \mathrm{mmHg}$. We identified $20 \mathrm{QQ}, 31 \mathrm{QR}$, and $16 \mathrm{RR}$ subjects with an allelic frequency of 0.53 for the $Q$ allele and 0.47 for the $\mathrm{R}$ allele. The observed genotypic frequency was in compliance with the Hardy-Weinberg equilibrium $(P=0.94)$. Among the three genotypic groups, there were no differences in age, gender distribution, body mass index, waist-hip ratio, or systolic and diastolic blood pressure (Table 2). The fasting lipid profile was

Table 2 Clinical characteristics by the Q223R polymorphism; mean with $95 \%$ confidence intervals in parentheses; ${ }^{a}$ geometric mean with $95 \%$ confidence intervals in parentheses.

\begin{tabular}{|c|c|c|c|}
\hline & $\mathbf{Q Q}(n=20)$ & $\mathbf{Q R}(n=31)$ & $\mathbf{R R}(n=16)$ \\
\hline Age (years) & $27(24,30)$ & $27(25,30)$ & $26(24,29)$ \\
\hline Females (\%) & $11(55 \%)$ & $16(52 \%)$ & $9(56 \%)$ \\
\hline Body mass index ${ }^{a}\left(\mathrm{~kg} / \mathrm{m}^{2}\right)$ & $23.98(22.34,25.74)$ & $23.96(22.59,25.43)$ & $24.60(22.62,26.76)$ \\
\hline Waist-hip ratio ${ }^{\mathrm{a}}(\mathrm{cm} / \mathrm{cm})$ & $0.790(0.755,0.827)$ & $0.799(0.772,1.209)$ & $0.812(0.770,0.857)$ \\
\hline Systolic blood pressure (mmHg) & $113(108,117)$ & $117(114,121)$ & $116(109,122)$ \\
\hline Diastolic blood pressure (mmHg) & $65(61,69)$ & $69(66,72)$ & $68(63,73)$ \\
\hline Total cholesterol $^{\mathrm{b}}$ (mg/dl) & $144(134,155)$ & $165(156,175)$ & $158(141,176)$ \\
\hline HDL cholesterol (mg/dl) & $47(42,53)$ & $52(47,56)$ & $45(40,51)$ \\
\hline LDL cholesterol ${ }^{\mathrm{C}}(\mathrm{mg} / \mathrm{dl})$ & $81(70,91)$ & $97(88,105)$ & $99(83,115)$ \\
\hline Triglycerides (mg/dl) & $83(63,102)$ & $84(68,101)$ & $74(57,92)$ \\
\hline
\end{tabular}

HDL, high density lipoprotein.

${ }^{\mathrm{b}} P=0.0287 ;{ }^{\mathrm{c}} P=0.0447$ 
notably different in total cholesterol $(P=0.0287)$ and low density lipoprotein (LDL) cholesterol $(P=0.0447$; Table 2). During the oral glucose tolerance test, differences were noted in the post-challenge plasma glucose concentration at $60 \mathrm{~min}(P=0.0212)$ and plasma insulin concentration at $60 \mathrm{~min} \quad(P=0.0372$; Table 3). The plasma glucose concentration at $90 \mathrm{~min}$ was marginally different $(P=0.0599)$.

Insulin sensitivity and $\beta$-cell function were assessed by a hyperglycemic clamp. The steady-state plasma glucose concentrations were almost identical among the three groups, while differences were observed in the insulin sensitivity index $(P=0.0180)$ and glucose clearance $(P=0.0220$; Table 3$)$. Since various covariates could potentially affect the insulin sensitivity, multivariate analysis was conducted by considering the influence of age, gender, body mass index, waist-hip ratio, systolic blood pressure, diastolic blood pressure, and Q223R polymorphism (Table 4). The Q223R polymorphism along with the body mass index, diastolic blood pressure, age, and gender explained 39.59\% and $39.40 \%$ of the variances in the insulin sensitivity index and glucose clearance respectively.

\section{Discussion}

Although the role of Q223R polymorphism at the leptin receptor gene has been examined in various studies, its impact on insulin sensitivity and the metabolic syndrome has not been investigated previously. The association of this polymorphism with insulin resistance was demonstrated in the univariate analysis and confirmed in the multivariate analysis. This polymorphism is an independent factor affecting $6-7 \%$ of insulin sensitivity. This association is in agreement with the fact that the subjects with the $\mathrm{R}$ allele are at risk for the metabolic syndrome, in which insulin resistance plays a major role. In contrast to the subjects without the $\mathrm{R}$ allele, the subjects with at least one $\mathrm{R}$ allele had insulin-resistant phenotypes, higher total and LDL cholesterol $(P=0.0287$ and $P=0.0447)$, higher plasma glucose concentration at 60 and $120 \mathrm{~min}(P=0.0212$ and $P=0.0599)$, and higher plasma insulin concentration at $60 \mathrm{~min}(P=0.0373)$. The $\mathrm{R}$ allele is therefore a risk factor for insulin resistance.

Although meta-analyses of the published reports conclude that there was no interaction of the Q223R polymorphism with obesity and its traits $(12,13)$, several reports showed the association of this polymorphism with various traits in obesity and metabolism (14$19)$. The latter association suggests a possible association between this polymorphism and insulin resistance as is demonstrated in this study. However, not all the studies are in agreement with the association of the $\mathrm{R}$ allele with obesity phenotypes. Interestingly, just like our population in this study, most of the positive associations of the $\mathrm{R}$ allele with obese or insulin-resistant phenotypes were observed in young (mean age $<30$ years old) and healthy populations $(14,16,19)$. In contrast, negative associations were found in postmenopausal women $(17,18)$ or in pathological states, such as impaired glucose tolerance (17) or overfeeding (15). It is possible therefore that this polymorphism contributes to the initiation of the events leading to insulin resistance in a subset of subjects. Additional studies are required to resolve this issue.

LEPR is a single transmembrane domain receptor with two cytokine domains, which binds to leptin (20). In Zucker fatty $(f a / f a)$ rats, a missense mutation (an A to C conversion at nucleotide position 806) in the extracellular domain of the LEPR gene results in a single amino acid change from $\mathrm{Q}$ to $\mathrm{P}$ at position 269 (21). The $f a$ mutation gives rise to a defective LEPR

Table 3 Oral glucose tolerance tests and hyperglycemic clamps by the Q223R polymorphism; mean with 95\% confidence intervals in parentheses; a geometric mean with $95 \%$ confidence interval in parentheses.

\begin{tabular}{|c|c|c|c|}
\hline & $\mathbf{Q Q}(n=20)$ & $\mathbf{Q R}(n=31)$ & $\mathbf{R R}(n=16)$ \\
\hline \multicolumn{4}{|l|}{ Oral glucose tolerance test } \\
\hline Fasting plasma glucose $(\mathrm{mmol} / \mathrm{l})$ & $4.58(4.41,4.76)$ & $4.71(4.59,4.84)$ & $4.69(4.51,4.88)$ \\
\hline Plasma glucose at $30 \mathrm{~min}(\mathrm{mmol} / \mathrm{l})$ & $7.27(6.71,7.83)$ & $7.62(7.14,8.11)$ & $6.99(6.32,7.66)$ \\
\hline Plasma glucose at $60 \mathrm{~min}^{\mathrm{b}}(\mathrm{mmol} / \mathrm{l})$ & $6.30(5.80,6.80)$ & $7.38(6.83,7.92)$ & $6.75(6.05,7.46)$ \\
\hline Plasma glucose at $90 \mathrm{~min}(\mathrm{mmol} / \mathrm{l})$ & $5.66(5.12,6.21)$ & $6.17(5.67,6.67)$ & $6.00(5.24,6.76)$ \\
\hline Plasma glucose at $120 \mathrm{~min}(\mathrm{mmol} / \mathrm{l})$ & $5.06(4.53,5.60)$ & $5.77(5.43,6.11)$ & $5.69(5.06,6.31)$ \\
\hline Fasting plasma insulin ${ }^{\mathrm{a}}(\mathrm{pmol} / \mathrm{l})$ & $55(48,64)$ & $58(52,65)$ & $64(56,74)$ \\
\hline Plasma insulin at $30 \mathrm{~min}^{\mathrm{a}}(\mathrm{pmol} / \mathrm{l})$ & $289(229,364)$ & $354(302,414)$ & $365(268,497)$ \\
\hline Plasma insulin at $60 \mathrm{~min}^{\mathrm{a}, \mathrm{c}}(\mathrm{pmol} / \mathrm{l})$ & $248(195,317)$ & $345(297,401)$ & $333(263,420)$ \\
\hline Plasma insulin at $90 \mathrm{~min}^{\mathrm{a}}(\mathrm{pmol} / \mathrm{l})^{\prime}$ & $204(163,255)$ & $229(187,280)$ & $254(179,362)$ \\
\hline Plasma insulin at $120 \mathrm{~min}^{\mathrm{a}}(\mathrm{pmol} / \mathrm{l})$ & $165(125,218)$ & $200(163,246)$ & $226(169,298)$ \\
\hline \multicolumn{4}{|l|}{ Hyperglycemic clamp } \\
\hline Steady-state plasma glucose $(\mathrm{mmol} / \mathrm{l})$ & $10.06(9.94,10.18)$ & $10.03(9.89,10.18)$ & $10.12(9.91,10.32)$ \\
\hline${\text { First-phase insulin response }{ }^{a}(\mathrm{pmol} / \mathrm{l})}^{\prime}$ & $1264(1014,1576)$ & $1470(1185,1825)$ & $1415(1135,1765)$ \\
\hline Second-phase insulin response ${ }^{a}(\mathrm{pmol} / \mathrm{l})$ & $330(262,415)$ & $344(297,399)$ & $393(302,513)$ \\
\hline Insulin sensitivity index ${ }^{a, d}\left(\mu \mathrm{m} / \mathrm{m}^{2}\right.$ per min per pmol) & $8.436(7.030,10.122)$ & $6.374(5.392,7.536)$ & $5.491(4.155,7.258)$ \\
\hline Glucose clearance ${ }^{\mathrm{a}, \mathrm{e}}\left(\mathrm{I} / \mathrm{m}^{2}\right.$ per min per pmol) & $0.839(0.700,1.006)$ & $0.645(0.539,0.772)$ & $0.543(0.414,0.713)$ \\
\hline
\end{tabular}

${ }^{\mathrm{b}} P=0.0212 ;{ }^{\mathrm{c}} P=0.0372 ;{ }^{\mathrm{d}} P=0.0180 ;{ }^{\mathrm{e}} P=0.0220$. 
Table 4 Multivariate analysis of the Q223R polymorphism on the insulin sensitivity index and glucose clearance.

\begin{tabular}{llll}
\hline $\begin{array}{l}\text { Dependent } \\
\text { variable }\end{array}$ & \multicolumn{1}{c}{$\begin{array}{c}\text { Co-variate } \\
\text { entered }\end{array}$} & Partial $\mathbf{r}^{2}$ & $\boldsymbol{P}$ \\
\hline Insulin sensitivity index & & \\
& Body mass index & 0.1265 & 0.0007 \\
& Diastolic blood pressure & 0.0766 & 0.0077 \\
& Age & 0.0600 & 0.0176 \\
Q223R polymorphism & 0.0737 & 0.0317 \\
Gender & 0.0464 & 0.0358 \\
Glucose clearance & & \\
$\quad$ Body mass index & 0.1045 & 0.0021 \\
& Diastolic blood pressure & 0.0982 & 0.0028 \\
Age & 0.0618 & 0.0162 \\
Q223R polymorphism & 0.0667 & 0.0436 \\
Gender & 0.0536 & 0.0247 \\
\hline
\end{tabular}

that is unable to constitutively activate the signal pathway and is also highly impaired for ligand-induced activation (22). Since both Q223R polymorphism and the $f a$ mutation occur in the first cytokine domain, it is highly possible that the Q223R polymorphism could also affect the function of LEPR. Furthermore, the conservation of this amino acid among the human, the rat, and the mouse suggests the possibility of a functional importance of this amino acid. A carefully designed study is required to examine the functional consequence of this polymorphism.

Insulin resistance plays a key role in the pathogenesis of type 2 diabetes. Although genetic influence is well recognized in type 2 diabetes, less than $50 \%$ of insulin sensitivity is inherited (23). Since type 2 diabetes is a multifactorial disease, each genetic factor will only have a very modest impact. We have observed that the Q223R polymorphism accounts for $6-7 \%$ of the variance in insulin sensitivity. Furthermore, this polymorphism has been shown to explain only $3-5 \%$ of body mass index and percent fat mass in a young Greek population (19). These observations indicate a very modest impact by this polymorphism.

In conclusion, we have present the first study of the Q223R polymorphism on insulin sensitivity. In a healthy and glucose-tolerant Caucasian population, this polymorphism is a modest but independent determinant of insulin sensitivity. The subjects with the $\mathrm{R}$ allele are at risk for the metabolic syndrome. However, this association does not imply a causal relationship between the Q223R polymorphism and insulin resistance. Nevertheless, the association suggests that the LEPR could play a role in the pathogenesis of insulin resistance. Confirmation studies in this ethnic group as well as other ethnic groups are required.

\section{Acknowledgements}

The work was supported in parts by grants from USPHS MO1RR00865 (UCLA-GCRC), NIH/NIDDK RO1DK52337 (K C C), and the American Diabetes
Association (K C C). We thank the staff of the General Clinical Research Center at the University of California, Los Angeles for their continued support. We also thank Rima Boyadjian for the insulin assays and Max $S$ Wang, Carol Yoon, George P Tsai, Jennifer M Ryu, Jennifer L McGullam and Jennifer E McCarthy for their laboratory assistance.

\section{References}

1 Thompson DB, Janssen RC, Ossowski VM, Prochazka M, Knowler WC \& Bogardus C. Evidence for linkage between a region on chromosome $1 \mathrm{p}$ and the acute insulin response in Pima Indians. Diabetes $1995 \mathbf{4 4} 478-481$.

2 Thompson DB, Ravussin E, Bennett PH \& Bogardus C. Structure and sequence variation at the human leptin receptor gene in lean and obese Pima Indians. Human Molecular Genetics 19976 675-679.

3 Pratley RE, Thompson DB, Prochazka M, Baier L, Mott D, Ravussin E et al. An autosomal genomic scan for loci linked to prediabetic phenotypes in Pima Indians. Journal of Clinical Investigation 1998101 1757-1764.

4 Hsueh WC, St Jean PL, Mitchell BD, Pollin TI, Knowler WC, Ehm MG et al. Genome-wide and fine-mapping linkage studies of type 2 diabetes and glucose traits in the Old Order Amish: evidence for a new diabetes locus on chromosome $14 \mathrm{q} 11$ and confirmation of a locus on chromosome 1q21-q24. Diabetes $200352550-557$.

5 Norman RA, Tataranni PA, Pratley R, Thompson DB, Hanson RL, Prochazka M et al. Autosomal genomic scan for loci linked to obesity and energy metabolism in Pima Indians. American Journal of Human Genetics $1998 \mathbf{6 2} 659-668$.

6 Quinton ND, Lee AJ, Ross RJ, Eastell R \& Blakemore AI. A single nucleotide polymorphism (SNP) in the leptin receptor is associated with BMI, fat mass and leptin levels in postmenopausal Caucasian women. Human Genetics 2001108 233-236.

7 Chiu KC, Chuang LM, Chu A \& Wang M. Transcription factor 1 and beta-cell function in glucose-tolerant subjects. Diabetes Medicine $200320225-230$.

8 Chiu KC, Cohan P, Lee NP \& Chuang LM. Insulin sensitivity differs among ethnic groups with a compensatory response in beta-cell function. Diabetes Care 200023 1353-1358.

9 DeFronzo RA, Tobin JD \& Andres R. Glucose clamp technique: a method for quantifying insulin secretion and resistance. American Journal of Physiology 1979237 E214-E223.

10 Mitrakou A, Vuorinen-Markkola H, Raptis G, Toft I, Mokan M, Strumph P et al. Simultaneous assessment of insulin secretion and insulin sensitivity using a hyperglycemia clamp. Journal of Clinical Endocrinology and Metabolism 199275 379-382.

11 Pimenta W, Korytkowski M, Mitrakou A, Jenssen T, Yki-Jarvinen $\mathrm{H}$, Evron W et al. Pancreatic beta-cell dysfunction as the primary genetic lesion in NIDDM. Evidence from studies in normal glucose-tolerant individuals with a first-degree NIDDM relative. Journal of the American Medical Association $1995 \mathbf{2 7 3}$ 1855-1861.

12 Heo M, Leibel RL, Boyer BB, Chung WK, Koulu M, Karvonen MK et al. Pooling analysis of genetic data: the association of leptin receptor (LEPR) polymorphisms with variables related to human adiposity. Genetics $20011591163-1178$.

13 Heo M, Leibel RL, Fontaine KR, Boyer BB, Chung WK, Koulu M et al. A meta-analytic investigation of linkage and association of common leptin receptor (LEPR) polymorphisms with body mass index and waist circumference. International Journal of Obesity and Related Metabolic Disorders 200226 640-646.

14 Stefan N, Vozarova B, Del Parigi A, Ossowski V, Thompson DB, Hanson RL et al. The Gln223Arg polymorphism of the leptin receptor in Pima Indians: influence on energy expenditure, 
physical activity and lipid metabolism. International Journal of Obesity and Related Metabolic Disorders 200226 1629-1632.

15 Ukkola O, Tremblay A, Despres JP, Chagnon YC, Campfield LA \& Bouchard C. Leptin receptor Gln223Arg variant is associated with a cluster of metabolic abnormalities in response to longterm overfeeding. Journal of Internal Medicine $2000 \mathbf{2 4 8}$ 435-439.

16 van Rossum CT, Hoebee B, van Baak MA, Mars M, Saris WH \& Seidell JC. Genetic variation in the leptin receptor gene, leptin, and weight gain in young Dutch adults. Obesity Research 2003 $11377-386$

17 Wauters M, Mertens I, Rankinen T, Chagnon M, Bouchard C \& Van Gaal L. Leptin receptor gene polymorphisms are associated with insulin in obese women with impaired glucose tolerance. Journal of Clinical Endocrinology and Metabolism $2001 \mathbf{8 6}$ 3227-3232.

18 Wauters M, Mertens I, Chagnon M, Rankinen T, Considine RV, Chagnon YC et al. Polymorphisms in the leptin receptor gene, body composition and fat distribution in overweight and obese women. International Journal of Obesity and Related Metabolic Disorders 200125 714-720.

19 Yiannakouris N, Yannakoulia M, Melistas L, Chan JL, KlimisZacas D \& Mantzoros CS. The Q223R polymorphism of the leptin receptor gene is significantly associated with obesity and predicts a small percentage of body weight and body composition variability. Journal of Clinical Endocrinology and Metabolism 2001 $864434-4439$.

20 Margetic S, Gazzola C, Pegg GG \& Hill RA. Leptin: a review of its peripheral actions and interactions. International Journal of Obesity and Related Metabolic Disorders 200226 1407-1433.

21 Takaya K, Ogawa Y, Isse N, Okazaki T, Satoh N, Masuzaki H et al. Molecular cloning of rat leptin receptor isoform complementary DNAs - identification of a missense mutation in Zucker fatty (fa/fa) rats. Biochemical and Biophysical Research Communications $199622575-83$.

22 White DW, Wang DW, Chua SCJ, Morgenstern JP, Leibel RL, Baumann $\mathrm{H}$ et al. Constitutive and impaired signaling of leptin receptors containing the Gln $\rightarrow$ Pro extracellular domain fatty mutation. PNAS 199794 10657-10662.

23 Chiu KC \& Martinez DS. Diabetes genes: human genome project and diabetes mellitus. In Principle of Diabetes Mellitus, edn 5, pp 123-137. Ed. L Poretsky. Boston: Kluwer Academic Publishers, 2002.

Received 24 September 2003

Accepted 29 January 2004 